\title{
CORONAVIRUS COVID-19 DISEASE, MENTAL HEALTH AND PSYCHOSOCIAL SUPPORT
}

\author{
GORDANA STANKOVSKA ${ }^{1}$, IMRAN MEMEDI² \& DIMITAR DIMITROVSKI ${ }^{3}$ \\ ${ }^{1}$ University of Tetova, Faculty of Medical Sciences, Ilinden nn, Tetovo, Republic of North Macedonia. \\ ORCID: 0000-0002-1280-3412, Email: gorstankovska@gmail.com \\ ${ }^{2}$ University of Tetova, Faculty of Medical Sciences, Ilinden nn, Tetovo, Republic of North Macedonia. \\ ORCID: 0000-0002-4175-5616, Email: dr.imran.memedi@gmail.com \\ ${ }^{3}$ Institute of Public Health, 50 Divizija 6, Skopje, Republic of North Macedonia. ORCID: 0000-0003- \\ 0662-7114, Email: ddimitrovski55@gmail.com
}

ABSTRACT: The current coronavirus (COVID-19) pandemic is a particular and rare situation. COVID-19 has affected and is likely to affect people from many countries, in many geographical locations. We are in the midst of a worldwide pandemic, with cities and even entire countries shutting down. The coronavirus has affected nearly every aspect of our lives, from school to work, to sports, to where we eat and what we do. All these changes affected people physically, but also psychologically.

It is understandable that during times like this, people may be feeling afraid, worried, anxious, and depressed due to the constantly changing alerts and media coverage regarding the spread of the virus. Hence, the main aim of our paper is to explore the linkage between the coronavirus COVID-19 disease and mental health conditions, such as stress, anxiety and depression. Everyone may experience fear of the consequences of the infection with a potentially fatal new virus, and might experience mental stress, anxiety, loneliness, depression. Based on experience from past global serious viral experiences, the development and implementation of mental health assessment, support, treatment, and services are crucial and pressing goals for the health response to the COVID-19 outbreak.

Human beings have an incredible ability to adapt and survive, through altruistic and 
co-operative means. So for each one of us is important to look after ourselves and each other.

KEYWORDS: coronavirus COVID-19, stress, anxiety, depression, psychosocial support

\section{INTRODUCTION}

“It's easy to blame, it's easy to politicize. It's harder to tackle a problem together, and find solutions together". (Tedros Adhanom Ghebreyesus, General Director of WHO)

Accounts of mental health and infectious diseases date to antiquity. Scientific appreciation for the many complex relationships between mental health problems and viral diseases has rapidly expanded only in recent decades (Coughlin 2011; Prince et al. 2007; Schuster, Bornovalova and Hunt 2012). Viral diseases and mental health conditions are not recognized among the largest categories of disease burden globally.

Since the end of December 2019, the Chinese city of Wuhan reported a novel pneumonia caused by coronavirus 2019 (COVID-19) which is spreading both nationally and internationally (Novel Coronavirus Pneumonia Emergency Response Epidemiology Team 2020:113). The virus has been named severe acute respiratory syndrome coronavirus 2 (SARS-CoV-2). COVID-19 rapidly spread from a single city to the entire country. The sheer speed of both the geographical expansion and the sudden increase in the number of cases, suppressed and quickly overwhelmed health and public health services in China, particularly in the city of Wuhan and the Hubei Province. Epidemic curves reflect what may be a mixed outbreak pattern, with early causes suggestive of a continuous common source, potentially a zoonotic spillover at the Huanan Seafood Wholesale Market, and later cases suggestive of a propagated source as the virus began to be transmitted from person-to-person (Battegay et al. 2020).

On January 30, the World Health Organization declared the novel coronavirus outbreak as an international emergency and on March 11, the WHO declared the global COVID-19 a pandemic (World Health Organization 2020). This new disease that emerged in Wuhan - China in late 2019, is currently having a significant impact worldwide. The numbers of cases are changing quickly and national governments of every country are rapidly adopting measures that are a precaution to minimize the risk of exposure and spread.

Since the outset, the government of every country has been working closely with the Ministry of Health and local public health units to provide evidence and expertise for informed decisions and policies in regard to surveillance, case control management, and infection control.

At this moment COVID-19 is affecting more than 27 countries, raising concern of widespread panic and increasing anxiety in individuals subjected to the (real or perceived) threat of the virus. Importantly, these concerns arise with all infections, including the flu and other agents, and the same universal precautions are needed and indicated for safety and the prevention of further transmission. There is widespread 
community transmission of COVID-19 in each country, meaning that the sources of new infections are unknown. Everyone everywhere should act as if they have been exposed to COVID-19.

Pandemics affect individuals and societies on many levels, causing disruption. It is normal to feel stress and worry when there is a health event happening in the community that is affecting people's wellbeing, such as the coronavirus disease (COVID-19). Fear and panic have also been linked to outbreaks. As concerns over the perceived threat grow, people may start to collect masks and other medical supplies. This is often followed by anxiety-related behaviors, insomnia, and overall lower perceived state of health. Every person may be particularly vulnerable to the effects of widespread panic and threat.

\section{THE MAIN CHARACTERISTICS OF THE CORONAVIRUS DISEASE 2019 (COVID-19)}

Coronaviruses are a group of viruses that can cause illness ranging from mild conditions, such as a cold, to more serious illnesses such as pneumonia (Nanshon et al. 2020). Recently, a new coronavirus was detected that had not been previously found in humans. The disease, called COVID-19, can be spread from person-to-person.

For the first time in 2003, the pathogen behind the SARS-CoV (severe acute respiratory syndrome) outbreak in China was identified as a coronavirus (Chan-Yeung and Rui-Heng 2003). That outbreak is believed to have started when a coronavirus was transmitted from animals, especially cats, to humans, resulting in a type of disease called zoonosis (Hung 2003:375). These viruses were underlined in 2012, when another virus was transmitted from camels to humans causing MERS-CoV (Middle East Respiratory Syndrome). That illness has killed 858 people to date, primarily in Saudi Arabia, representing approximately 34 percent of those infected (Hajjar, Memish, and Mcintosh 2013; De Wit et al. 2016).The comparisons with the current virus showed significant differences and similarities. Both MERS-CoV and SARS-CoV have much higher fatality rates ( $40 \%$ and $10 \%$ respectively).

Although the current SARS-CoV-2 (also referred to as $2019-\mathrm{nCoV}$ ), shares $79 \%$ of its genome with SARS-CoV, it appears to be more transmissible (Phan et al. 2020). The virus activates immune cells and induces the secretion of inflammatory cytokines and chemokines into pulmonary vascular endothelial cells. The mean incubation period is 14 days, with the $95^{\text {th }}$ percentile of distribution at 5.5 days, though uncertainty remains. Studies have shown effective person-to-person transmission of 2019-nCoV even in the presence of isolation efforts in medical facilities (Phan et al. 2020). Transmission in a health setting is a very serious threat. While further study is required, it appears that asymptomatic persons are also potential sources of 2019-nCoV infection (Wan et al. 2020; Rothe et al. 2020).

There are two ways a coronavirus can be transmitted via air. In a droplet form, the coronavirus is airborne for a few seconds after someone sneezes or coughs. It is able to travel only a short distance before gravitational forces pull it down. Someone close enough for the virus particles to reach in that brief period can therefore be infected. 
It can be anyone who comes into contact with virus-containing droplets that fall onto a surface. The new coronavirus can survive on surfaces for several hours; hence is the importance of hand-washing after touching a surface in a public place. The Wuhan scientists concluded that the virus aerosol is a potential transmission pathway (Jiang et al. 2020).

Huang et al. (2020:499) first reported clinical features of 41 patients confirmed to be infected with COVID-19 on January 2, 2020. The initial symptoms included fever, cough, dyspnea, myalgia or fatigue, sputum production, headache, hemoptysis and diarrhea. Most people with COVID-19 have mild to moderate symptoms and fully recover without complications. Less commonly, COVID-19 may lead to pneumonia, hospitalization or death.

People who are at most risk for severe illness are adults aged 50 or older, or those who have chronic health conditions, such as: lung disease, heart disease, diabetes, cancer, and weakened immune system.

\section{COVID-19, OUTBREAKS AND PANDEMICS}

It is a frightening time. We are in the midst of a worldwide pandemic, with cities and even entire countries shutting down. Some of us are in areas that have already been affected by coronavirus. Others are bracing for what may come. And all of us are watching the headlines and wondering: "What is going to happen next?".

COVID-19 has and is likely to affect people from many countries, in many geographical location. The governments of all countries decided to restrict personal movements, public events, and business activities of their people, media outlets worldwide have accelerated the fear-based headline machine into overdrive. There are hourly updates of new cases, possible deaths, and official briefings, as well as prognostication about future calamity (World Health Organization 2020).

Many streets in cities around the world are empty. Flights to and from affected parts of the world have been grounded. Scientific or business conferences have been cancelled. Museums are closed. People have to stay at home. It is clear that, when public health authorities have to face outbreaks, national and international policies and interventions have been used. Getting people to cooperate towards the goal of contingent self-imposed quarantines, washing hands, limiting travel and gatherings, reducing number of free riders to a minimum and avoiding extreme risk perceptions (panic or anxiety) is as important as closing schools and increasing the number of beds in intensive care units. At this moment, it is very difficult to tell how many lives were saved with the actions to reduce the pandemic.

COVID-19 is new virus and has not been well understood yet. We do not have a vaccine for coronavirus, but we have antiviral therapy, which might be effective against coronavirus and maybe life will return to normal in every part of the world.

\section{MENTAL HEALTH IMPACTS OF CORONAVIRUS COVID-19}

Public health emergencies, such as the outbreak of the coronavirus disease 2019 
(COVID-19), are a stressful time for both people and communities. Fear and anxiety about a disease can lead to social stigma toward people, places or things. For example, stigma and discrimination can occur to people with a disease, such as COVID-19, within a population or a nation, even though not everyone belongs to that population or to a region that is specifically at risk for the disease. It is very clear that stigma hurts everyone by creating fear or anger towards other people. COVID-19 has wrecked our way of life in a manner that probably has not been seen for a long time. There has been a lot of fear, anxiety and stress related to this new situation in our life.

In fact, the coronavirus has affected nearly every aspect of our lives from school to work, to sports, to where we eat and what we do. All these changes being forced upon us can stir up anxiety within us. Facing these critical situations, everyone is at risk of developing psychological distress and mental health symptoms such as anxiety, depression, and loneliness (Barlow and Michelle 2000). There are likely to be multiple biological and behavioral pathways that account for linkages between mental health conditions and viral disease, such as coronavirus disease 2019 (COVID-19) and the specific mechanisms can vary by viral disease. Mental conditions such as depression can delay help-seeking or reduce the likelihood of detecting other health condition including communicable diseases (Basco, Krebaum, and Rush 1997). Depression and psychological stress have shown to have a number of biological effects including reduced cell-mediated immunity and increased inflammatory processes (Heymann 2008). A further issue is that coronavirus can directly affect the brain and result in mental health conditions such as stress, anxiety or depression.

Communities can be affected by COVID-19 in many ways. People are separated from their loved ones, due to illness or death. Health workers need to deal with a high workload and a lot of stress. Those associated with COVID-19 can be vulnerable to social stigma, which is worsening their distress and isolation. In fact, whole communities nay experience the fear and suffering that disease outbreaks often cause. Potential mental health impacts on people who are directly affected include:

- Increased anxiety for oneself and others;

- Psychological distress;

- Social isolation;

- Interruption of employment or study;

- Impact on normal daily routines and functioning.

Most people will manage with the support of family and friends, but others may need some extra help to keep things on track.

\section{COVID-19, STRESS AND POSTTRAUMATIC STRESS DISORDER}

Stress is a normal psychological response to an abnormal situation. As such, it is a part and a parcel of our lives. It enables our body to adapt to the multiplicity of positive or negative events that we experience, such as birth, marriage, loss of employment, etc. 
Stress comes and goes on its own, depending onthe involved factors (Beck and Sloan 2012).

The outbreak of the coronavirus disease (COVID-19) may be stressful for people. Everyone reacts differently to stressful situations. The way a person responds to the outbreak can depend on his/her background, the things that make him/her different from other people, and the community the person lives in.

Stress during an infectious outbreak can include:

- Fear and worry about our own health and the health of our loved ones;

- Changes in sleep or eating patterns;

- Problems with memory or concentration;

- Worsening of chronic health problems;

- Increased use of alcohol, tobacco, or other things.

At the same time, people experience psychologically traumatic stressors "outside the range of usual human experience". Many of those subjected to psychologically traumatic stressors, experience them in dreams or memory with an associated unpleasant feeling, changes in affect and experience of trauma usually dominant in frequency and intensity, and themselves do not represent signs of posttraumatic stress disorder.

Individuals exposed to trauma, such as a coronavirus pandemic, fail to recover spontaneously and experience lingering symptoms that mirror their initial reaction to an event. These individuals develop an acute stress disorder or reaction that greatly interferes with their ability to return to their family and their social and work routines (Coughlin 2012). Within a month or so, such acute reactions usually remit, and the person returns to his or her pre-trauma routine, with a restored a state of homeostasis. For others, this acute reaction fails to remit and symptoms persist, becoming chronic, often debilitating posttraumatic stress disorder (Blaunchard and Buckley 1999).

\section{RELATIONSHIP BETWEEN COVID-19 AND ANXIETY}

Contrary to fear, which is a response to a well-defined and very real threat, anxiety is a response to a vague or unknown threat. Anxiety is manifested when we believe that a dangerous or unfortunate event may take place and one expects it. Everyone experiences anxiety at their own individual degree and intensity. The way an anticipated event is perceived will greatly influence the intensity of the experience of anxiety.

The symptoms of anxiety are persistent are not restricted to, or markedly increased, in any particular set of circumstances. With headlines warning us of international terrorism, global warming, economic uncertainty, or viral diseases, such as COVID-19, all of us are likely to be a little more anxious these days. As an everyday emotion, anxiety - "the fight or flight" response can be a good thing, prompting us to take extra precautions. But when anxiety persists in the absence of a need to fight or flee, it can not only interfere with our daily lives, but it can also undermine our physical health 
(Wittchen and Hoyer 2001). Evidence suggests that people with anxiety disorder are at greater risk for developing a number of acute or chronic medical conditions. They also have more severe symptoms and a greater risk of death when they become ill (Brown and Barlow 2001).

While the nature of most differential experiences is not yet clear, evidence suggests that stressful life plays a significant role in the onset and persistence of anxiety. Blazer, Hughes and George (2016:1181) noted that the occurrence of one or more negative life events increased the risk of developing anxiety in the following year. Among the other theories, uncontrollability over the environment (Barlow 2001), psychosocial trauma (Borkovec 1994), and insecure attachment to caregivers (Borkovec 1994) have been conceptualized as risk factors for anxiety.

Anxiety can appear in a variety of physical, psychological, emotional and behavioral ways for any given individual in this period of the unknown COVID-19. There is a characteristic pattern which consists of the following features (Bystritsky et al. 2013):

- Autonomic over-activity which is most often experienced as sweating, palpitations, dry mouth, dizziness, etc.;

- Psychological and emotional arousal, which can be manifested as virus-related worries and insecurity, feelings of being overwhelmed by events, self-verbalization that does not always reflect reality, negative vision of things or daily events, feelings of discouragement, insecurity, sadness, anger;

- Sleep disturbances, which include difficulty falling asleep and persistent worrying thoughts. Some people might have terrors and wake up suddenly feeling extremely anxious.

- Behavioral symptoms, such as: difficulty concentrating, irritability or aggression, crying, withdrawal or insularity, difficulty in making decisions.

Patients with confirmed or suspected COVID-19 may experience fear of the consequences of the infection with a potentially fatal new virus, and those in quarantine might experience boredom and loneliness. In addition, symptoms of the infection, such as fever, hypoxia, and cough, as well as adverse effects of the treatment, such as insomnia caused by corticosteroids, could lead to worsening anxiety and mental distress. COVID-2019 has been repeatedly described as a killer virus, which has perpetuated the sense of danger and uncertainty among health workers and the public (Weshling et al. 2020). In the early phase of the SARS outbreak, a range of psychiatric morbidities including depression, anxiety, panic attack, psychomotor excitement, psychotic symptoms, delirium, and even suicidality, were reported (Lee, Wong, and McAlonan 2007). Furthermore, mandatory contact tracing and 14 days quarantine, which form a part of public health responses to the COVID-19 pneumonia outbreak, could increase patient's anxiety and guilt about the effects of contagion, quarantine, and stigma on their families and friends.

At the same time, health professionals are vulnerable to high risk of infections and mental health problems. They may also experience fear of contagion and spreading of 
the virus to their families, friends, or colleagues. They experience high level of stress, anxiety and depressive symptoms (Wang et al. 2020). Similar concerns about the mental health, psychological adjustment, and recovery of healthcare workers treating and caring for patients with COVID-19 are now arising everywhere.

\section{FRAMEWORK FOR UNDERSTANDING THE LINKAGE BETWEEN DEPRESSION AND COVID-19}

We are living in the dark time of health where we are surrounded by thousands of contagious viruses, bacteria and other pathogens in the environment that use our bodies as their long-term home. Once these microbes have insinuated themselves into our metabolisms, they frequently remain there for life, where they can slowly or rapidly degrade our physical and mental health. Pathogens living in an individual's body will reduce the person's mental and physical activities. Our bodies are considerably overburdened with persisted viral infections which often alter our physiology.

The burden of depression is rising both for the individual, the family, and for the society. Currently most people who are treated for depression are partially responsive or non-responsive. New tools are needed. One of these tools involves a focus on the infections that are often associated with depression (Mason, Mathews, and Han 2013).

On the other side, we did not know anything about the mechanism of the linking between COVID-19 and depression among people. Although the effects of the coronavirus on mental health have not been systematically studied, it is anticipated that COVID-19 will have rippling effects, especially based on current public reactions. It is normal to feel sad about some of the news we are hearing, because people are dying. This is a very scary and concerning situation. This new virus in endemic and pandemic forms, is a major factor in morbidity and mortality globally.

Depression is a state of low mood aversion to activity that can affect a person's thoughts and behavior, feelings and physical wellbeing (American Psychiatric Association 2013). Depressed people may feel sad, anxious, empty, hopeless, helpless, worthless, guilty, irritable or restless. They may lose interest in activities that once were pleasurable, experience loss of appetite or begin overeating, or experience problems of concentrating, remembering details or making decisions, and may contemplate or even attempt suicide. Insomnia, excessive sleeping, fatigue, loss of energy, aches, pains or digestive problems that are resistant to treatment may be present (Attkisson and Zich 1990).

Depression in this coronavirus pandemic is a normal reaction to certain life events. It is absolutely natural for each of us to feel fear, sad, loneliness and isolation during this time.

As Peter Kinderman (2020) said:

COVID-19 will affect us all. Our lives are changing quickly, we are isolating ourselves and social distancing which cannot be good for our mental health. The inevitable uncertainty will also put pressure or our emotions and resilience. It is normal to feel afraid, depressive and worried in the face of uncertainty and adversity, but there are also things we can do to look after our mental health and 
wellbeing during these times.

\section{THE ROLE OF PSYCHOSOCIAL SUPPORT FOR MANAGING STRESS, ANXIETY AND DEPRESSION DURING CORONAVIRUS DISEASE(COVID-19)}

It is understandable that during times like this, people may be feeling afraid, worried, anxious, and overwhelmed by the constantly changing alerts and media coverage regarding the spread of the virus. So it is very important to stay informed, to follow mental health and wellbeing tips and strategies and to continue to look after ourselves and each other during these difficult times.

Psychosocial treatment consists of strategies that target excessive, uncontrollable stress, concern and persistent excessive arousal. Psychiatrists and psychologists are uniquely situated to help both their patients and the great community understand the potential impact of the virus and help patients, families and society deal with this latest threat. Treatment plans, progress, reports and status updates should be given to the person and his/her family. Emotional and behavioral response are a part of an adaptive response to extraordinary stress, and psychotherapy techniques based on the stress-adaptive model might be helpful (Folkman and Greer 2000). It has also been recognized, that after this large COVID-19 pandemic, survivors will need prolonged mental health care when facing the task of rebuilding their lives (Keane, Weathers and Fox 2000).

From the standpoint of care and support, it is very important to recognize three phases of a/an endemic/pandemic (before, during and after). Therefore, we try to present the main psychosocial manifestations in an epidemic, broken down by phases and corresponding actions.

Psychological assistance services, including telephone, internet and application-based counseling or intervention, have been widely deployed by local and national mental health institutions in a response to the COVID-19 outbreak. Hence the availability of transparent appropriate, and timely information is vital for the emotional restraint of family members and for keeping the general population calm (Sandman and Lanard 2005). So, the healthy sector should coordinate with law enforcement and humanitarian aid workers for crowd control. Entry to health care facilities should also be controlled.

Each one of us is part of a community, so it is our human nature to care for one another, as we, in turn, seek the social and emotional support of others. 
Table 1. Phases/psychosocial manifestations in the population and mental health actions

\begin{tabular}{|c|c|}
\hline $\begin{array}{l}\text { Phases/psychosocial manifestations in the } \\
\text { population }\end{array}$ & Mental health actions \\
\hline $\begin{array}{l}\text { Before: } \\
\text { - Sense of inevitability, with a high level of ten- } \\
\text { sion in the population, } \\
\text { - Maximization of preexisting characteristics } \\
\text { (positive or negative); } \\
\text { - Worry, fear, tension, anxiety, depression, insom- } \\
\text { nia... }\end{array}$ & $\begin{array}{l}\text { - Communicate risk to the population, with emphasis on } \\
\text { vulnerable groups (children, adolescents, old persons, } \\
\text { persons who contracted the disease and survived, persons } \\
\text { with chronic physical illness). } \\
\text { - Locate personnel trained in mental health. } \\
\text { - Establish psychosocial support and counseling groups. } \\
\text { - Detect psychosocial risk factors. } \\
\text { - Encourage collective spirit and support community par- } \\
\text { ticipation. } \\
\text { - Organize mental health services for an adequate emer- } \\
\text { gency response (mobile teams, crisis intervention units } \\
\text { and services in general hospitals). }\end{array}$ \\
\hline $\begin{array}{l}\text { During: } \\
\text { - Loss of initiative. } \\
\text { - Feelings of fear, worry, vulnerability. } \\
\text { - Adaptation to changes in the usual patterns of } \\
\text { life (restricted movement, wearing masks, reduc- } \\
\text { tion in direct physical contact, closure of schools } \\
\text { or universities, closure of shops....). } \\
\text { - Anxiety, depression, stress, panic attacks, agita- } \\
\text { tion, somatic disorder of psychological origin. }\end{array}$ & $\begin{array}{l}\text { - Evaluation of the psychosocial needs of the population. } \\
\text { - Support of the core actions of early detection, reporting, } \\
\text { care and containment. } \\
\text { - Mass communication, information and guidance on: what } \\
\text { is happening, what is being done, and what the people } \\
\text { should do. } \\
\text { - Provide psychosocial care and support (individual and } \\
\text { group-based) for affected people, families, and communi- } \\
\text { ties. } \\
\text { - Create opportunities for mutual support in the commu- } \\
\text { nity. } \\
\text { - Create a menu of personal self-care activities that the per- } \\
\text { son enjoys, such as spending time with family, exercising or } \\
\text { reading a book. } \\
\text { - Take a break from media coverage of CovID-19. } \\
\text { - Support everyone to be connected with others. } \\
\text { - Promote work rotation and organize working hours ap- } \\
\text { propriately. } \\
\text { - Take time to talk with children or teens about the } \\
\text { CoviD-19 in a way that they can understand. } \\
\text { - Protect human rights (migrants, refugees, prisoners, peo- } \\
\text { ple with disabilities). } \\
\text { - Specialized services for pandemic settings. }\end{array}$ \\
\hline $\begin{array}{l}\text { After: } \\
\text { - Fear of a new epidemic. } \\
\text { - Social and mental health conditions: depression, } \\
\text { posttraumatic stress, violence, depression, alco- } \\
\text { hol or drug abuse. } \\
\text { - A slow, progressive recovery process begins. }\end{array}$ & $\begin{array}{l}\text { - Maintain a mass communication strategy to facilitate } \\
\text { recovery. } \\
\text { - Implement individual and group-based mental health } \\
\text { care for the affected persons, families and communities. } \\
\text { - Support that new life projects should be fostered and } \\
\text { encouraged. }\end{array}$ \\
\hline
\end{tabular}

Source: own elaboration. 


\section{CONCLUDING REMARKS}

In this review we summarized studies and experiences which indicate important relationship between stress, anxiety, depression and viral diseases such as the coronavirus disease 2019 (COVID-19).

In today's world, a microbial disaster is no longer a possibility, but a certainty: "As human impact on the earth increases exponentially, the chances for unpleasant surprises from the microbial world will also grow. The virus spreads quickly, because no one has any significant immunity to the novel strain and the illness it causes can be usually severe" (Schnurr and Green 2004:21).

The COVID-19 outbreak that began in China in December 2019, caused more than 779.741 cases and 38.721 deaths in the world (Worldometer 2020, Last updates March $31,2020)$. The WHO has reported more than 220.000 cases and 11.987 deaths associated with COVID-19 in the European region (Kluge 2020). That means that globally roughly about 6 out of every 10 cases, and 7 out of every deaths, are reported from the European region (Kluge 2020).

Global society is more interconnected than ever, and emerging pathogens do not respect geopolitical boundaries. Proactive investment in public infrastructure and capacity is critical to improve international surveillance, cooperation, coordination and communication about this major outbreak and to be even better prepared to respond to future new public health threats.

Most of the people do not have resources and mental strength to adapt to this type of situation. We are faced with "an invisible enemy", our lives continue to be disrupted and social distancing becomes necessary. The fear and anxiety will increase, everyone has unreal thoughts about the new day and everyone feels isolated or depressive. During the outbreak, "generalized fear and fear-induced over-reactive behavior were common among the public", while depression, anxiety and post-traumatic stress disorder all emerged. The negative effects of stigmatizing a language, such as attaching a region or an ethnicity to the virus, or blaming people for transmission, exacerbate the sense of fear at a macro level. Hence, a sense of hope instead of fear could allow leaders and everyday citizens to better cooperate with another which each other is a vital element in defeating this outbreak. As a society, we must work together with a sense of empathy. As individuals, we must inform ourselves of the facts, stay connected to the people we love and be kind to each other.

Among the many experiences discussed regarding psychosocial interventions in the event of COVID-19 outbreak in the world, special attention has been dedicated to:

- The need for involving communities before, during, and after the epidemic/ pandemic;

- To investigate in the training and supervision of workers to provide psychosocial support and mental health care;

- To improve the care of vulnerable groups of persons;

- To integrate the psychosocial and mental health interventions within the 
framework of public health.

In any biological disaster, themes of fear, anxiety, depression and stigmatization are common and may act as barriers to appropriate medical and mental health interventions (Pierini and Stuifbergen 2010). Based on experience from past serious novel pneumonia outbreaks globally and the psychosocial impact of viral epidemics, the development and implementation of mental health assessment, support, treatment, and services are crucial and pressing goals for the health response to the 2019-nCoV outbreak.

Human beings have an incredible ability to adapt and survive, through altruistic and co-operative means. So for each one of us is important to look after ourselves and each other.

FUNDING: This research received no external funding.

CONFLICT OF INTEREST: The authors declare no conflict of interest.

\section{REFERENCES}

American Psychiatric Association. 2013. Diagnostic and statistical manual of mental disorders. ( $4^{\text {th }}$ ed.). Washington, DC: Author.

Attkisson, Clifford C. and Jane M. Zich. 1990. "Depression screening in primary care: Clinical needs and research challenges.” Pp. 3-11 in Depression in primary care: Screening and detection, edited by C. C. Attkinson and J. M. Zich. New York: Routledge.

Barlow, David H. 2001. Anxiety and its disorders: The nature and treatment of anxiety and panic. New York: Guilford Press.

Barlow, David H. and Michelle G. Craske. 2000. Mastery of your anxiety and panic. San Antonio, TX: Psychological Corporation.

Basco, Monica R., Stewen R. Krebaum, and John A. Rush. 1997. “Outcome measures of depression.” Pp. 191-198 in Measuring patient changes in mood, anxiety, and personality disorders: Toward a core battery, edited by H. H. Strupp, L. M. Horowitz, and M. J. Lumbert. Washington, DC: American Psychological Association.

Battegay, Manuel, Richard Kuehl, Sutter Tschudin-Sutter, Hans H. Hirsch, and Richard Neher. 2020. "2019-Novel coronavirus (2019-nCoV): Estimating the case fatality rate-a word of caution.” Swiss Medicine Weekly 14-18. DOI:10.4414/ smw.2020.20203.

Beck, Gavie J. and Denise M. Sloan. 2012. "A comprehensive overview of treatment, stress disorders, ranging from diagnosis and etiology to assessment and management.” Pp. 245-265 in The Oxford Handbook of Traumatic Stress Disorder, edited by D. M. Sloan. Oxford: OUP.

BlaunchardErick R. and Timothy C. Buckley. 1999. "Psychophysiological assessment 
of posttraumatic stress disorders.” Pp. 248-266 in Posttraumatic stress disorder: A comprehensive text, edited by P. A. Saigh and J. D. Bremmer. Boston: Allyn and Bacon.

Blazer, G. Dan, Dana Hughes, and Linda K. George. 2016. "Stressful life events and the onset of generalized anxiety disorder syndrome.” American Journal of Psychiatry 144:1178-1183.

Borkovec, D. Thomas. 1994. "The nature, functions, and origins of worry.” Pp. 5-34 in Worrying; Perspectives on theory, assessment, and treatment, edited by G. Davey and F. Tallis. New York: Wiley.

Brown, Timothy A. and David H. Barlow. 2001. “Generalized anxiety disorder.” Pp. 137182 in Clinical handbook of psychological disorders: A step-by-step treatment manual, edited by D. H. Barlow. New York: Guilford Press.

Bystritsky, Alexander, Sahib S. Khatsa, Michael E. Cameron, and Jason Schiffman. 2013. "Current diagnosis and treatment of anxiety disorders." Journal of Clinical Psychiatry 30(1):30-38.

Chan-Yeung, Moira and Xu Rui-Heng. 2003. “SARS: Epidemiology.” Respirology 8(1): 9-14. DOI: 10.1046/j.1440-1843.2003.00518.x.

Coughlin, Steven A. 2012. Post-traumatic stress disorder and chronic health condition. Washington, DC: American Public Health Association.

Coughlin, Steven A. 2011. "Post-traumatic stress disorder and the care of persons living with HIV/AIDS.” The Open Health Services and Policy Journal 4:39-41.

De Wit, Emmie, Neelitje Van Doremalen, Darryl Falzarano, and Vincet J. Munster. 2016. "SARS and MERS: Recent insights into emerging coronaviruses." Natural Review of Microbiology 14(8):523-534.

Folkman, Susan and Steven Greer. 2000. "Promoting psychological well-being in the face of serious illness: when theory, research and practice inform each other." Psycho-oncology 9:11-19.

Hajjar, Sami A, Ziad A. Memish, and Kenneth Mcintosh. 2013. "Middle East Respiratory Syndrome Coronavirus (MERS-CoV): A Perpetual Challenge.” Annals of Saudi Medicine 33(5): 427-436.

Heymann, L. David. 2008. Control of Communicable Diseases. Washington, DC: American Public Health Association.

Huang, Chaolin, Yeming Wang Lili Ren, Jiaping Zhao, and Yl Hu. 2020. "Clinical features of patients infected with 2019 novel coronavirus in Wuhan, China." Lancet 295(10223): 497-516. DOI: 10.1016/S0140-6736(20)30183-5

Hung, Lee Shiu. 2003. "The SARS Epidemic in Hong Kong: What Lessons Have We Learned?" Journal of the Royal Society of Medicine 96(8): 374-78. DOI: 10.1258/ jrsm.96.8.374.

Jiang, Fang, Liehua Deng, Liangging Zhang, Chi Cheung, and Zhengyan Xia. 2020. "Review of clinical characteristics of coronavirus disease 2019 (COVID-19).” Journal of General Internal Medicine. Retrieved March 4, 2020 (https://ink.springer.com/ article/10.1007/s11606-020-05762-w).

Lee, Man, Clive Wong, and Greinne McAlonan. 2007. "Stress and psychological distress among SARS survivors 1 year after the outbreak.” Canadian Journal of Psychiatry 
52: 233-240.

Keane, Terence, Bureau F. Weathers, and Everette B Fox. 2000. "Diagnosis and assessment.” Pp. 176-192 in Effective treatments for PTSD: Practice guidelines from the International Society for Traumatic Stress Study, edited by E. B. Fox, T. Keane and M. J. Friedman. New York: Guildford Press.

Kinderman, Peter. 2020. "Looking after your mental health during COVID-19." Retrieved March 20, 2020 (https://www.liverpool.ac.uk/institute-of-life-sciences/ staff/peter-kinderman).

Kluge, Hans Henri P. 2020. "Physical and mental health key to resilience during COVID-19 pandemic.” Retrieved 26 March, 2020 (http://www.euro.who.int/ en/about-us/regional-director/statements/statement-physical-and-mentalhealth-key-to-resilience-during-covid-19-pandemic).

Mason, Lisa H., Michael J. Mathews, and Dong Y. Han. 2013. "Neuropsychiatric symptom assessments in toxic exposure." Psychiatric Clinics of North America 36:201208. DOI: $10.1016 /$ j.psc.2013.02.001

Nanshon, Chen, Zhou Min, Dong Huan, Qu Jieming, Gong Fengjyum, and Han Yang. 2020. "Epidemiological and clinical characteristics of 99 cases of 2019 novel coronavirus pneumonia in Wuhan, China: a descriptive study.” Lancet January 30, 2020. DOI: https://doi.org/10.1016/S0140-6736(20)30211-7

Novel Coronavirus Pneumonia Emergency Response Epidemiology Team. 2020. "Vital surveillances: The epidemiological characteristics of an outbreak of 2019 novel coronavirus 2019 (COVID-2019)-China.” China CDC Weekly 2(8):113-118. Retrieved February 20, 2020 (http://weekly.chinacdc.cn/en/article/id//e53946e341e9-9a9b-fea8db1a8f5).

Pierini David, and Alexa Stuifbergen. 2010. "Psychological resilience and depressive symptoms in older adults diagnosed with post-polio syndrome.” Rehabilitation Nursing Journal 35:167-75.

Phan, Lan T., Thuong V. Nguyen, Quang C. Luong, Think V. Nguyen, and Hiew T. Nguyen. 2020. "Importation and human-to-human transmission of a novel coronavirus to Vietnam.” New England Journal of Medicine 382:872-876.

Prince, Martin, Vikram Patel, Shekhar Saxena, Mario Maj, Joanna Maselko, Michael R. Phillips, and Atif Rahman. 2007. "No health without mental health.” Lancet 70(9590): 859-877.

Rothe, Camilla, Mirjam Schunk, Peter Sothman, Gisela Bretzel, Guenter Proeschl, Claudia Wallrauch, Thorbjorn Zimmer, Verena Thiel, and Cristian Janke. 2020. "Transmission of 2019-nCoV infection from an asymptomatic contact in Germany.” New England Journal of Medicine 382: 370:371. DOI: 10.1056/NEJMc20001468

Sandman, Peter M. and Jody Lanard. 2005. "Bird Flu: Communicating the risk: Perspectives in health, the magazine of the Pan American Health Organization.” Health Promotion Practice 9(4): 54-59.

Schuster, Randi, Marina Bornovalova, and Evan Hunt. 2012. "The influence of depression on the progression of HIV: direct and indirect effects." Behavioral Medicine 36:123-145.

Schnurr, Paula P. and Robert L. Green. 2004. “Understanding relationship among trau- 
ma, post-traumatic stress disorder and health outcomes." Adverse Mind Body Medicine 20:18-29.

Wan, Yushun, Jian Shang, Rachel Graham, Ralph S. Barie, and Fang Li. 2020. “Receptor recpgnition by novel coronavirus from Wuhan: An analysis based on decade-long structural studies of SARS." Journal of Virology 94(7): forthoming.

Wang, Chen, Peter W. Horby, Frederich G. Hayden, and George F. Gao. 2020. "A novel coronavirus outbreak of global health concern.” Lancet 395(10223): 470-473. DOI: $10.1016 / S 0140-6736 / 20 / 30185-9$

Weshling, Nang, Xu Yauli, Gao Ruqin, Lu Roujlan, Horn kai, Wu Guizten, and Tan Wenjie. 2020. "Detection of SARS-CoV-2 in different types of clinical specimens." JAMA March 11, 2020. DOI: 10.1001/jama.2020.3786

Wittchen, Hans U. and Jurgen Hoyer. 2001. "Generalized anxiety disorder: Nature and course." Journal of Clinical Psychiatry 62(11):15-19.

World Health Organization. 2020. "Coronavirus disease (COVID-19) outbreak.” Western Pacifik. Retrieved March 29, 2020 (https://www.who.int/westernpacific/emergencies/covid-19).

Worldometer. 2020. COVID-19 coronavirus pandemic. Retrieved March 31, 2020 (https://www.worlddometer-info-coronavirus pandemic).

Zunyou, Wu and Jeniffer M. McGoogan. 2020. "Characteristics of and Important Lessons from the Coronavirus Disease 2019 (COVID-19) Outbreak in China." JAMA. Retrieved February 24, 2020 (http://vproxy.ws/?cdURL=aHR0cHM6Ly9qYW1hbmV0d29yay5jb20vam91cm5hbHMvamFtYS9mdWxsYXJ0aWNsZS8yNzYyMTMw). DOI:10.1001/jama.2020.2648)

\section{BIOGRAPHICAL NOTE}

Stankovska Gordana is a professor of clinical psychology at the Institute of Psychology and Psychiatry at the Faculty of Medical Sciences, Republic of North Macedonia.

Memedi Imran is a PhD Candidate of psychiatry at the Faculty of Medical Sciences, Republic of North Macedonia.

Dimitrovski Dimitar, MhD, is a biochemistry researcher at the Institute of Public Health, Republic of North Macedonia.

OPEN ACCESS: This article is distributed under the terms of the Creative Commons Attribution NonCommercial License (CC BY-NC 4.0) which permits any non-commercial use, and reproduction in any medium, provided the original author(s) and source are credited 
